11,13

\title{
Двухстадийная конверсия кремния в наноструктурированный углерод методом согласованного замещения атомов
}

\author{
(C) С.А. Кукушкин ${ }^{1}$, А.В. Осипов ${ }^{1,2}$, Н.А. Феоктистов ${ }^{2}$ \\ ${ }^{1}$ Санкт-Петербургский национальный исследовательский университет \\ инорормационных технологий, механики и оптики, \\ Санкт-Петербург, Россия \\ ${ }^{2}$ Институт проблем машиноведения РАН, \\ Санкт-Петербург, Россия \\ E-mail: sergey.a.kukushkin@gmail.com \\ (Поступила в Редакцию 20 сентября 2018 г. \\ В окончательной редакции 5 октября 2018 г.)
}

Рассмотрен принципиально новый метод получения эпитаксиальных слоев наноструктурированного углерода на кремниевых подложках. Эпитаксиальный рост в случае, казалось бы, несовместимых решеток достигается за счет конверсии кристалла методом согласованного замещения атомов, при котором не разрушается общая структура связей между атомами. На первой стадии конверсии первая половина атомов кремния $\mathrm{Si}$ согласованно замещается на атомы углерода С за счет реакции $\mathrm{Si}$ с газом CO, при этом получается эпитаксиальный слой кубического карбида кремния SiC-3C. На второй стадии конверсии оставшаяся половина атомов $\mathrm{Si}$ согласованно замещается на атомы С за счет реакции $\mathrm{SiC}$ с газом $\mathrm{CF}_{4}$. В зависимости от ориентации поверхности кремния, давления газа-реагента, температуры и времени роста, получаются углеродные структуры с различными свойствами, от наноалмазов до нанотрубок и луковичного углерода. Ключевой особенностью данного метода является то, что подложка упорядочивает образующиеся структуры, используя исходные химические связи между атомами в кремнии. Термин „согласованно“ означает, что новые химические связи образуются одновременно и согласованно с уничтожением старых связей. Представлены данные по дифракции электронов и анализу рамановских и эллипсометрических спектров полученных образцов наноструктурированного углерода на кремниевых подложках. Обсуждаются два конкурирующих механизма роста.

Работа выполнена при использовании оборудования Уникального стенда (УНО) „Физика, химия и механика кристаллов и тонких пленок“ ФГУП ИПМаш РАН.

DOI: $10.21883 /$ FTT.2019.03.47255.261

\section{1. Введение}

Конверсия одного кристалла в другой за счет химической реакции, как метод получения тонких пленок, в принципе, известна уже давно. Одной из первых работ в этой области можно считать работу [1], в которой кристалл кремния превращался в карбид кремния с помощью реакции

$$
\mathrm{Si}+\mathrm{CH}_{4}=\mathrm{SiC}+2 \mathrm{H}_{2} .
$$

Этот метод неоднократно применялся в последующие десятилетия, но никому не удавалось получить этим методом качественную эпитаксиальную пленку, только поликристаллическую. В работе [2] впервые было дано объяснение тому, почему растет только поликристаллическая пленка. Тщательное изучение механизмов данной конверсии показало, что на самом деле этот процесс полностью аналогичен стандартному росту $\mathrm{SiC}$ методом CVD на поверхности кремния [2]. Атомы кремния из кристалла $\mathrm{Si}$ медленно диффундируют через слой растущего $\mathrm{SiC}$ и вступают в реакцию $\mathrm{c}^{\mathrm{CH}_{4}}$ на поверхности пленки. Рост $\mathrm{SiC}$ происходит по классическим законам диффузии [2], а максимальная глубина, где удается получить $\mathrm{SiC}$, примерно равна $100 \mathrm{~nm}$. Огромное несоответсвие решеток $\mathrm{SiC}$ и $\mathrm{Si}$ принципиально не позволяет получить эпитаксиальную пленку $\mathrm{SiC}$. B связи с актуальностью роста нановискеров [3] в последние несколько лет большой интерес проявляется как к прямой конверсии кристалла $\mathrm{Ga}_{2} \mathrm{O}_{3}$ в $\mathrm{GaN}$ за счет реакции c $\mathrm{NH}_{3}[4,5]$ :

$$
\mathrm{Ga}_{2} \mathrm{O}_{3}+2 \mathrm{NH}_{3}=2 \mathrm{GaN}+3 \mathrm{H}_{2} \mathrm{O}
$$

так и к обратной конверсии [4]

$$
2 \mathrm{GaN}+(3 / 2) \mathrm{O}_{2}=\mathrm{Ga}_{2} \mathrm{O}_{3}+\mathrm{N}_{2} .
$$

Слои оксидов меди $\mathrm{Cu}_{2} \mathrm{O}$ и $\mathrm{CuO}$ и нановискеры $\mathrm{CuO}$ в работе [6] получали конверсией из меди

$$
\begin{gathered}
4 \mathrm{Cu}+\mathrm{O}_{2}=2 \mathrm{Cu}_{2} \mathrm{O}, \\
2 \mathrm{Cu}_{2} \mathrm{O}+\mathrm{O}_{2}=4 \mathrm{CuO} .
\end{gathered}
$$

Как известно, многообразие структуры и свойств углеродных наноматериалов определяется уникальной способностью атомов углерода к различным типам гибридизации электронных оболочек: плоскостной „графеновой, 
$s p^{2}$-типа“, пространственной „алмазной, $s p^{3}$-типа“ и линейной „карбиновой - $s p$-типа“. Возможность создания углеродных наноматериалов с предельно близким расположением областей, имеющих различный тип гибридизации электронных оболочек, делает метод конверсии особенно актуальным при получении углеродных слоев.

Углеродные структуры пытались получить конверсией из $\mathrm{SiC}$. В частности, в уже упомянутой работе [1] предлагалось окислять кристаллический $\mathrm{SiC}$

$$
\mathrm{SiC}+\mathrm{O}_{2}=\mathrm{C}+\mathrm{SiO}_{2} \text {. }
$$

Однако, как было показано позже, в этом случае растет только аморфный графит. В 90-е годы аналогичную реакцию, но с хлором, использовали для получения нанопористого углерода [7]

$$
\mathrm{SiC}+2 \mathrm{Cl}_{2}=\mathrm{C}+\mathrm{SiCl}_{4} \text {. }
$$

В 2001 г. Ю. Гогоци предложил использовать эту же реакцию для получения уже наноалмазов [8]. Как указали авторы, хлор „выедает“ весь кремний из карбида кремния, а оставшийся углерод группируется в какиелибо углеродные структуры. В этой же статье было показано, что если в хлор ничего не добавлять, то также, как и в [7] образуются аморфно-поликристаллические нанопористые углеродные структуры, близкие к луковичным (onion-like carbon). Но если к хлору добавить большое количество водорода, то вырастают структуры, содержащие углерод с $s p^{3}$ гибридизацией размером порядка $1 \mathrm{~nm}$, но основная масса углерода будет все равно аморфной и поликристаллической. Эта идея получила дальнейшее развитие в работе [9], в которой предполагалось, что после вытравливания хлором атомов $\mathrm{Si}$ из $\mathrm{SiC}-6 \mathrm{H}$ атомы С должны „сами собой“ сгруппироваться в алмазы. Увы, во всех перечисленных выше случаях тонкие пленки, которые получались в результате конверсии, были либо аморфными, либо поликристаллическими. Эпитаксии, когда подложка задавала бы ориентацию пленке, не было никогда. Исключение составляет быть может недавний эксперимент по росту вискеров $\mathrm{GaN}$ из $\mathrm{Ga}_{2} \mathrm{O}_{3}$ [5], но данные структуры не были сплошными. Причина, по которой не было эпитаксии, очень проста - все без исключения перечисленные реакции разрушали имеющуюся кристаллическую структуру подложки, то есть в этих реакциях вначале разрушались старые химические связи, а затем через некоторое время образовывались новые химические связи. По химической терминологии такие топохимические реакции называют несогласованными.

В настоящей работе слои наноструктурированного углерода предлагается получать из кремния только за счет согласованных реакций замещения, в которых новые атомы встают на место старых, сохраняя всю структуру связей, то есть новые связи создаются одновременно с разрушением старых связей. Углерод из кремния предлагается получать в две стадии (см. рис. 1). На первой стадии из кремния согласованным образом образуется кубический политип карбида кремния $\mathrm{SiC}-3 \mathrm{C}$, т. е. первая половина атомов $\mathrm{Si}$ согласованно заменяется на атомы C за счет реакции замещения с монооксидом углерода $\mathrm{CO}$, после чего решетка „схлопывается“ с сохранением всей структуры (рис. 1). На второй стадии вторая половина атомов $\mathrm{Si}$ (т.е. атомы $\mathrm{Si}$ в $\mathrm{SiC}$ ) согласованно заменяется на атомы С за счет реакции замещения с тетрафторидом углерода $\mathrm{CF}_{4}$ (рис. 1), после чего решетка вновь „схлопывается“, но в какую структуру неизвестно, так как это зависит от многих факторов. Первая стадия конверсии за счет реакции $\mathrm{Si}$ c CO разработана авторами несколько лет назад [10], причем в 2017 году методами квантовой химии было доказано, что в реакции замещения

$$
2 \mathrm{Si}(\text { crystal })+\mathrm{CO}(\text { gas })=\mathrm{SiC}(\text { crystal })+\mathrm{SiO}(\text { gas })
$$

новые связи создаются именно согласованным образом за счет промежуточного состояния $\mathrm{Si}-\mathrm{O}-\mathrm{C}$ в виде треугольника [11], что принципиально отличает эту реакцию от всех реакций, перечисленных выше. Поэтому в данной работе все внимание будет сосредоточено на абсолютно новой второй стадии конверсии, а именно, реакции замещения

$$
\mathrm{SiC}(\text { crystal })+\mathrm{CF}_{4}(\text { gas })=2 \mathrm{C}(\text { crystal })+\mathrm{SiF}_{4}(\text { gas }) .
$$

Эта реакция также является согласованной, в отличие от реакции Гогоци [6], где связи просто не могут сохраниться, так как хлор выедает весь кремний, уничтожая алмазоподобную структуру связей. На второй стадии конверсии, в отличие от первой, при схлопывании решетки структура графита оказывает серьезную конкуренцию структуре алмаза, поэтому конечная структура зависит от типа проводимости исходного кремния, ориентации его поверхности, давления газа и других факторов, что и исследуется в настоящей работе.

\section{2. Синтез образцов и методы исследования}

Слои наноструктурированного углерода выращивались на подложках $\mathrm{Si}(100), \mathrm{Si}(110), \mathrm{Si}(111) n$ - и $p$-типа методом согласованного замещения атомов. На первой стадии конверсии использовалась топохимическая реакция замещения между монокристаллической подложкой $\mathrm{Si}$ и газообразным монооксидом углерода CO (8) [10-13]. Первая стадия конверсии протекала в вакуумной печи при температуре $T=1200-1300^{\circ} \mathrm{C}$ и давлении $\mathrm{CO} p_{\mathrm{CO}}=0.1-3$ Torr в течении $15-30 \mathrm{~min}$. При этом образовывалась эпитаксиальная пленка $\mathrm{SiC}$ кубического политипа 3С толщиной от 50 до $200 \mathrm{~nm}$ в зависимости от ориентации подложки и давления $\mathrm{CO}$ [14]. Под пленкой $\mathrm{SiC}-3 \mathrm{C}$ в объеме $\mathrm{Si}$ происходило образование пустот и полостей (см. рис. 2), вызванное тем, что объем ячейки $\mathrm{SiC}$ в два раза меньше объема ячейки $\mathrm{Si}$ (рис. 1). На качество $\mathrm{SiC}$ в пленке они не 


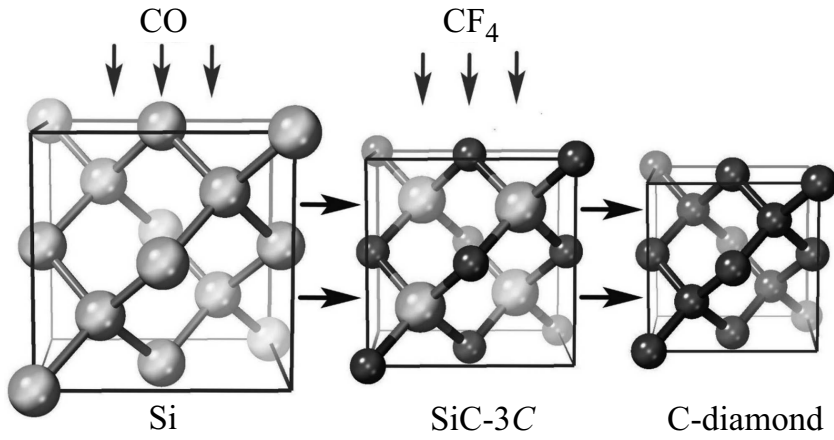

Рис. 1. Схематическое представление двухстадийной конверсии кристалла кремния в кристалл алмаза. Большие светлые шарики - атомы $\mathrm{Si}$, маленькие темные - атомы С. На первой стадии конверсия происходит за счет реакции замещения с СO, на второй - за счет реакции замещения с $\mathrm{CF}_{4}$. Поскольку на обеих стадиях замещение атомов происходит согласованно, т.е. разрушение старых связей и образование новых связей протекает одновременно и согласованно, то общая структура связей сохраняется и остается тетраэдрической.

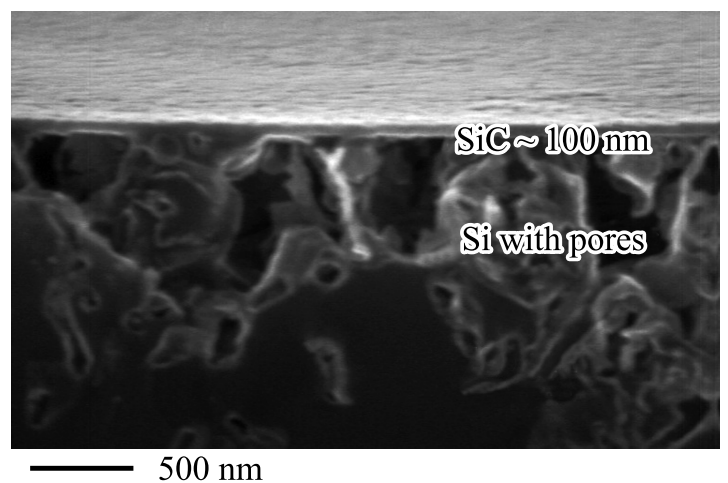

Рис. 2. Микрофотография слоя $\mathrm{Si}-3 \mathrm{C}$, выращенного на $\mathrm{Si}$ на первой стадии конверсии. Под слоем Si-3C толщиной $\sim 100 \mathrm{~nm}$ имеются поры и пустоты, также частично заполненные $\mathrm{SiC}$ различных политипов.

влияют. Важно подчеркнуть, что полости и пустоты в $\mathrm{Si}$ частично заполнены $\mathrm{SiC}$ на глубине вплоть до нескольких микрон [14], т.е. образец, полученный на первой стадии конверсии, содержит достаточно большое количество $\mathrm{SiC}$.

Отличительной особенностью слоев $\mathrm{SiC}-3 \mathrm{C}$, получаемых методом согласованного замещения атомов, является достаточно высокая концентрация углеродновакансионных структур [13]. Из-за упругих напряжений в системе ( $\mathrm{Si}$ сжат, $\mathrm{SiC}$ растянут), а также из-за излишней потери кремния путем вывода его из системы газом $\mathrm{SiO}(8)$, карбид кремния содержит кремниевые вакансии. При высоких температурах синтеза одному из соседних атомов углерода выгодно перепрыгнуть на место кремниевой вакансии и образовать связи с 3 соседними атомами $\mathrm{C}$ [13]. Колебания связей $\mathrm{C}-\mathrm{C}$ регистрируются в инфракрасном спектре как на отражение, так и на пропускание, их частота равна $960 \mathrm{~cm}^{-1}$, что полностью согласуется с теоретическими результатами, полученными методом функционала плотности [13]. Кроме того, углеродно-вакансионные структуры оказывают заметное влияние на диэлектрическую проницаемость $\mathrm{SiC}$, делая его менее прозрачным, что также обнаружено экспериментально $[13,15]$. Весьма возможно, что такие почти плоские кластеры из 4 атомов углерода рядом с кремниевой вакансией играют важную роль в упорядочении вначале слоя $\mathrm{SiC}$, а затем слоя углерода.

На второй стадии конверсии (9) полученные образцы $\mathrm{SiC}-3 \mathrm{C} / \mathrm{Si}$ обрабатывались в вакуумной печи тетрафторидом углерода $\mathrm{CF}_{4}$ при температуре $T=1300-1400^{\circ} \mathrm{C}$ и давлении $p_{\mathrm{CF}_{4}}=10-100$ Torr в течении $15-100 \mathrm{~min}$. При этом в зависимости от ориентации исходной подложки, ее температуры, времени конверсии и давления $\left.p_{\mathrm{CF}_{4}}\right)$ на поверхности образца образовывались наноуглеродные структуры различного типа.

Полученные структуры исследовались методами эллипсометрии в интервале энергий фотонов $0.7-6.5 \mathrm{eV}$ (эллипсометр М-2000 с вращающимся компенсатором компании J.A. Woollam), дифракции быстрых электронов на отражение (ускоряющее напряжение $50 \mathrm{kV}$ ), рамановской спектроскопии (длина света лазера $532 \mathrm{~nm}$ ), сканирующей электронной микроскопии.

\section{3. Экспериментальные результаты и их обсуждение}

Выполненные эксперименты показали, что двухстадийной конверсией из кремния можно получать ориентированные слои наноструктурированного углерода толщиной 50-200 nm (рис. 3). Толщина и свойства слоев наноструктурированного углерода сильно зависят от ориентации исходной подложки, температуры конверсии и времени конверсии. В интервале температур $1200-1400^{\circ} \mathrm{C}$ чем выше температура, тем качественнее и толще растет углеродный слой. В настоящей работе описываются результаты, полученные при температуре второй стадии конверсии $T=1350^{\circ} \mathrm{C}$ (чтобы избежать каких-либо эффектов предплавления кремниевой подложки). В отличие от первой стадии конверсии, где слой $\mathrm{SiC}$ образуется очень быстро, вторая стадия протекает заметно медленнее. Это связано, очевидно, с тем, что молекулы $\mathrm{CF}_{4}$ заметно крупнее молекул $\mathrm{CO}$ и содержат больше атомов, поэтому им сложнее диффундировать, тем более, что диффундировать в углероде сложнее, чем в $\mathrm{SiC}[14]$.

На рис. 3, а приведена микрофотография среза образца $\mathrm{C} / \mathrm{SiC} / \mathrm{Si}(111)$. На первой стадии конверсии при $T=1300^{\circ} \mathrm{C}$ и давлении $p_{\mathrm{CO}}=0.7$ Torr была выращена пленка $\mathrm{SiC}$ толщиной $\sim 200 \mathrm{~nm}$. Как уже упоминалось, под этой пленкой в порах и пустотах также находилось большое количество $\mathrm{SiC}$ [14]. Вторая стадия конверсии длилась $25 \mathrm{~min}$ при $T=1350^{\circ} \mathrm{C}$ и давлении $p_{\mathrm{CF}_{4}}=25$ Torr. При этом толщины $\mathrm{SiC}$ и С оказались примерно по $80 \mathrm{~nm}$. На рис. $3, b$ приведен срез образца 
$a$

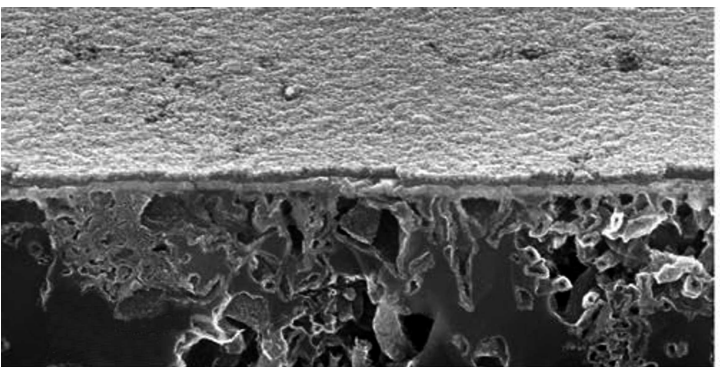

$500 \mathrm{~nm}$

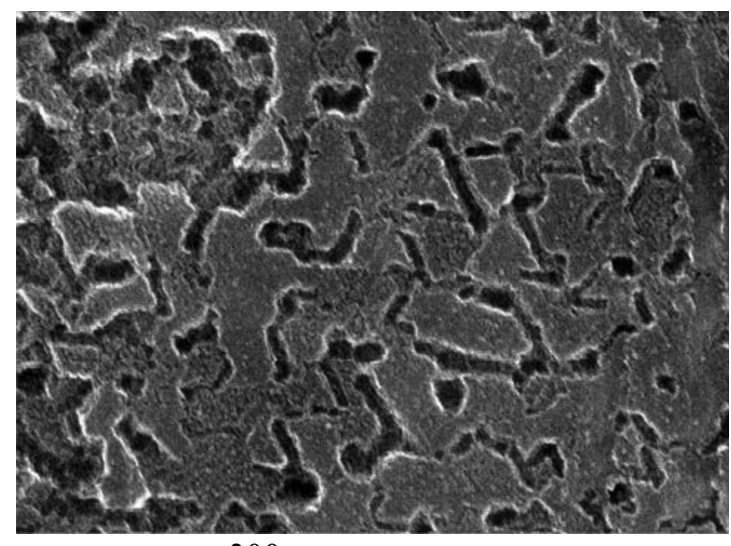

$300 \mathrm{~nm}$

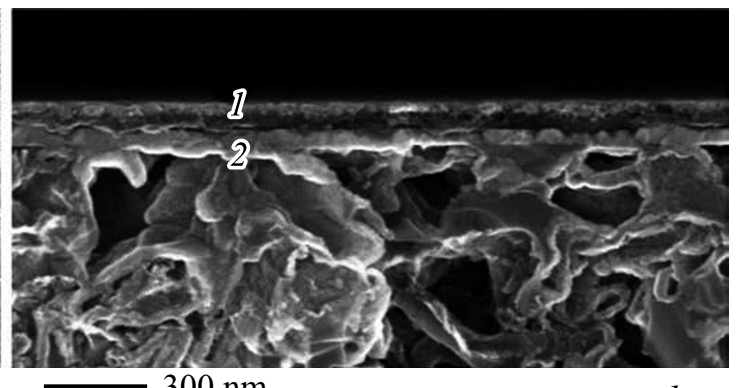

$d$

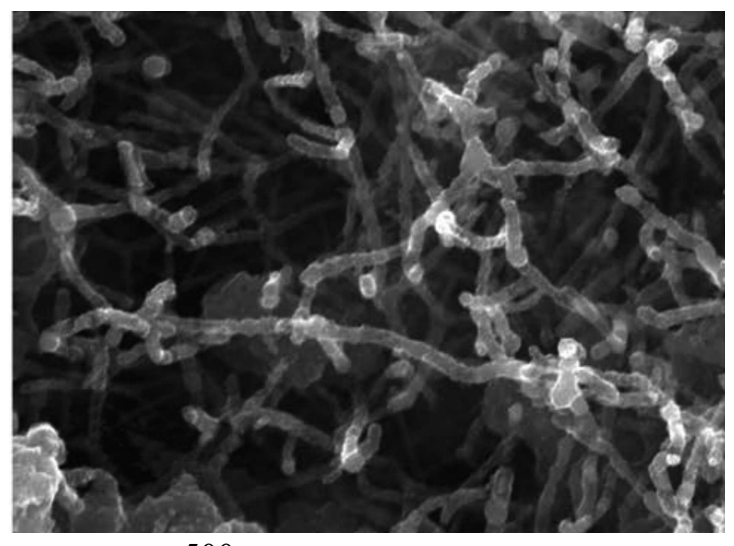

$500 \mathrm{~nm}$

Рис. 3. Микрофотографии различных образцов $\mathrm{C} / \mathrm{SiC} / \mathrm{Si}$, полученных двухстадийной конверсией из $\mathrm{Si}$. На рисунке $(b)$ цифрами 1 и 2 обозначены слои $\mathrm{C}$ и $\mathrm{SiC}$ толщиной 90 и $70 \mathrm{~nm}$ соответственно.

$\mathrm{C} / \mathrm{SiC} / \mathrm{Si}(110)$. Толщина слоя $\mathrm{SiC}$ после первой стадии конверсии была равна $100 \mathrm{~nm}$ (толщина надежно определяется методом эллипсометрии [15]. После второй стадии конверсии при давлении $p_{\mathrm{CF}_{4}}=50$ Torr и времени $20 \mathrm{~min}$ толщины слоев $\mathrm{C}$ и $\mathrm{SiC}$ примерно равны $90 \mathrm{~nm}$ и $70 \mathrm{~nm}$ соответственно. При увеличении времени второй стадии конверсии толщина пленки $\mathrm{SiC}$ уменьшается вплоть до полного растворения, а толщина пленки C непрерывно увеличивается даже после исчезновения пленки $\mathrm{SiC}$.

По нашему мнению, это говорит о том, что слой наноструктурированного углерода растет по двум параллельным механизмам роста одновременно. Первый механизм - это чистое превращение решетки пленки $\mathrm{SiC}$ в решетку C путем согласованного замещения атомов, как показано на рис. 1. Второй механизм, побочный, осуществляется за счет химической реакции газа $\mathrm{CF}_{4} \mathrm{c}$ атомами $\mathrm{Si}$, которые диффундируют из верхнего слоя подложки $\mathrm{Si}$ или слоя $\mathrm{SiC}$ к поверхности растущей пленки наноструктурированного углерода. Если структуры, растущие по первому механизму, должны быть высокоориентированы, так как вся исходная решетка монокристалла $\mathrm{SiC}-3 \mathrm{C}$ ориентирует их, то во втором случае углеродные структуры должны быть ориентированы гораздо хуже из-за энергетической выгодности графита. Поэтому итоговая пленка наноструктурированного углерода является результатом конкуренции этих двух механизмов роста, каждый из которых сильно зависит от ориентации исходного кремния, температуры и давления $\mathrm{CF}_{4}$. Поверхность пленки наноструктурированного углерода также сильно меняется в зависимости от условий роста. В частности, на $\mathrm{Si}(111)$ при больших давлениях $p_{\mathrm{CF}_{4}}>50$ Torr и малых временах роста $t<20 \mathrm{~min}$ углеродная пленка растет почти плоской (рис. 3, $c$, средняя шероховатость $\sim 1 \mathrm{~nm})$. На $\mathrm{Si}(110)$ при давлениях $p_{\mathrm{CF}_{4}} \sim 15-40$ Torr и времени роста $t>30 \mathrm{~min}$ образуются структуры в виде нанотрубок (рис. $3, d$, средняя шероховатость $\left.\sim 10^{2} \mathrm{~nm}\right)$. Часто реализуются промежуточные варианты, когда на поверхности углеродной пленки хаотично расположены маленькие кристаллики размером 50-200 $\mathrm{nm}$ (средняя шероховатость $\sim 10 \mathrm{~nm}$ ).

Рамановский спектр получаемых образцов также очень разнообразен и может быть условно разделен на три типа. При малых временах второй стадии конверсии $t<20 \mathrm{~min}$, за редким исключением, образцы имеют рамановский спектр типа I (рис. 4), состоящий из двух толстых линий $D$-band и $G$-band. В частности, данный конкретный спектр получен от образца $\mathrm{C} / \mathrm{SiC} / \mathrm{Si}(111)$ при $t=15 \mathrm{~min}, p_{\mathrm{CF}_{4}}=60$ Torr. Как правило, образцы типа I являются прозрачными, например, при толщине слоя углерода $\sim 100 \mathrm{~nm}$ высота рамановских линий $\mathrm{Si}$ и $\mathrm{SiC}$ почти не изменяется (рис. 4). Эллипсометрический анализ также дает полную прозрачность слоя углерода типа I в диапазоне энергий фотонов вплоть 


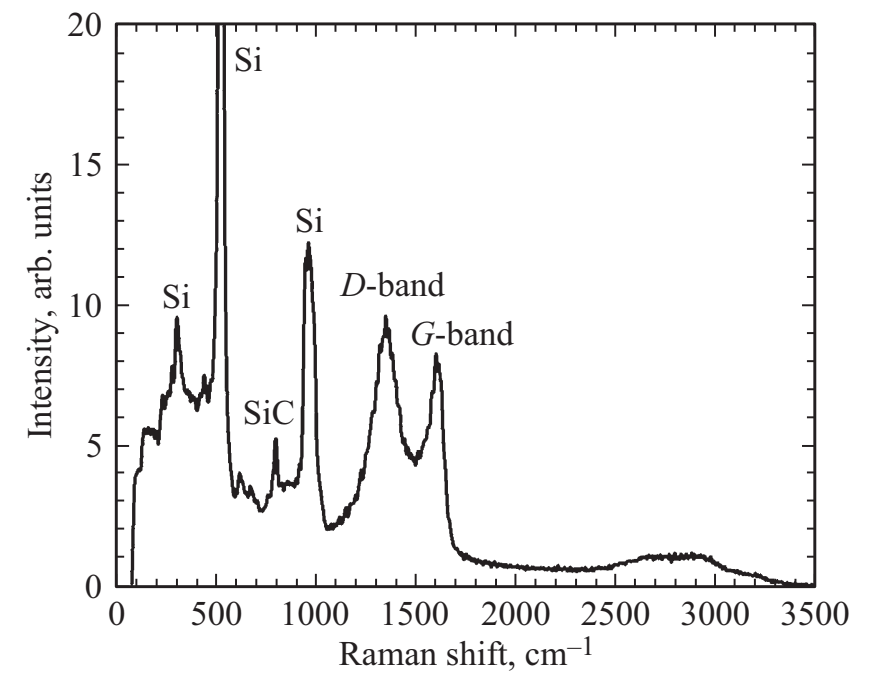

Рис. 4. Рамановский спектр типа I от прозрачного слоя углерода на $\mathrm{SiC} / \mathrm{Si}$.

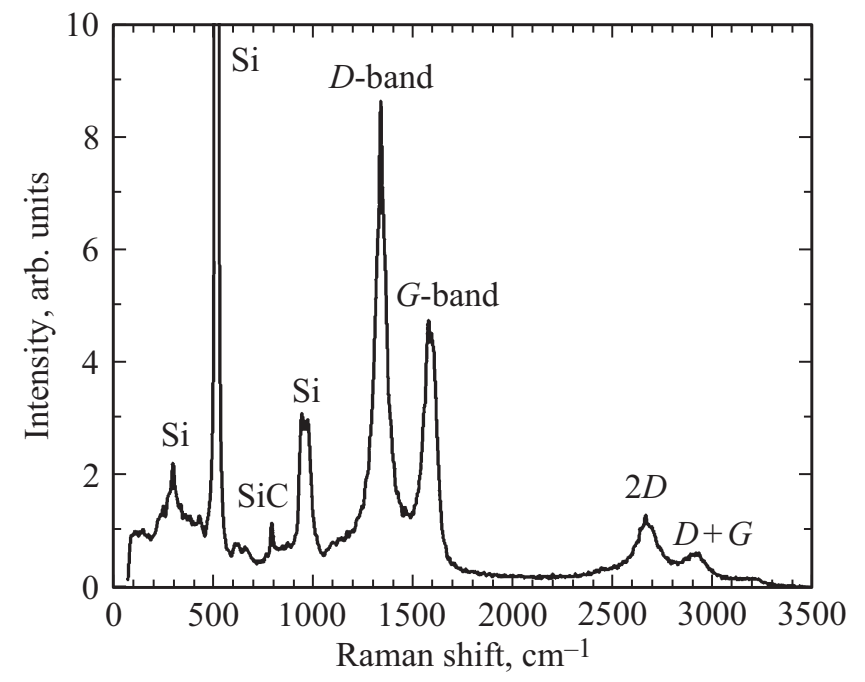

Рис. 5. Рамановский спектр типа II от полупрозрачного слоя углерода на $\mathrm{SiC} / \mathrm{Si}$.

до $6.5 \mathrm{eV}$. Пик $D$-band у типа I соответствует частоте $1350 \mathrm{~cm}^{-1}$, пик $G$-band соответствует частоте $1600 \mathrm{~cm}^{-1}$. Рамановский спектр слоев типа I похож на спектр наноалмазов, в частности, детонационных алмазов $[16-$ 19] и шаровидных неограненных алмазов (ballas) $[18,19]$.

При увеличении времени второй стадии конверсии рамановский спектр типа I может не измениться (при этом прозрачность ухудшается), а может перейти в спектр типа II (рис. 5) или типа III (рис. 6). Обратных переходов, а также переходов II $\leftrightarrow$ III зарегистрировано не было. Слои углерода с рамановским спектром типа II можно назвать полупрозрачными, линии $\mathrm{SiC}$ и $\mathrm{Si}$ попрежнему хорошо видны (рис. 5). Эллипсометрические измерения показывают, что слои типа II менее прозрачные, чем слои типа I. Линии $D$-band и $G$-band становятся заметно уже, пик $D$-band становится заметно выше пика
$G$-band, кроме того, оба пика сдвигаются влево. Пик $D$-band у типа II соответствует частоте $1345 \mathrm{~cm}^{-1}$, пик $G$-band соответствует частоте $1585 \mathrm{~cm}^{-1}$. Кроме них, отчетливо видны пики $D^{\prime}\left(1620 \mathrm{~cm}^{-1}\right), 2 D\left(2690 \mathrm{~cm}^{-1}\right)$, $D+G\left(2930 \mathrm{~cm}^{-1}\right)$ (рис. 5). Данный спектр получен от образца $\mathrm{C} / \mathrm{SiC} / \mathrm{Si}(111)$ при $t=25 \mathrm{~min}, p_{\mathrm{CF}_{4}}=60 \mathrm{Torr}$, причем исходная подложка $\mathrm{Si}$ имела отклонение от поверхности (111), равное $4^{\circ}$. Важно отметить, что на вицинальных $4^{\circ}$ поверхностях (111) углеродный слой всегда получается более прозрачным, чем на (111) без отклонения.

Рамановский спектр типа III соответствует непрозрачному слою наноструктурированного углерода (рис. 6). Линия кремния в данном случае не видна вообще. Линии $D\left(1345 \mathrm{~cm}^{-1}\right), G\left(1575 \mathrm{~cm}^{-1}\right), 2 D\left(2685 \mathrm{~cm}^{-1}\right)$ имеют примерно одинаковую высоту, так же видны линии $D^{\prime}\left(1620 \mathrm{~cm}^{-1}\right), D+G\left(2930 \mathrm{~cm}^{-1}\right)$ и линии $2430 \mathrm{~cm}^{-1}, 3220 \mathrm{~cm}^{-1}$ (рис. 6). Данный спектр получен от образца $\mathrm{C} / \mathrm{SiC} / \mathrm{Si}(110)$ при $t=50 \mathrm{~min}, p_{\mathrm{CF}_{4}}=60$ Torr. Рамановский спектр слоев типа III похож на спектр луковичного углерода (onion-like carbon) или углеродных нанотрубок $[18,19]$. Поэтому мы предполагаем, что слои типа I и типа II содержат углерод с преимущественной $s p^{3}$-гибридизацией, а слои типа III содержат углерод с преимущественной $s p^{2}$-гибридизацией. С этой гипотезой согласуется тот факт, что наноалмазы часто переходят в луковичный углерод, а обратных переходов не бывает $[18,19]$. В работе [20] показано, что если химическую реакцию проводить в присутствии водорода, то из наноалмазов можно получить более крупные кристаллики с алмазной структурой.

На рис. 7 показана зависимость диэлектрической проницаемости углеродного слоя типа III от энергии фотонов, измеренная эллипсометром M-2000 J.A. Woollam с вращающимся компенсатором. Интересно отметить, что как вещественная, так и мнимая часть диэлектри-

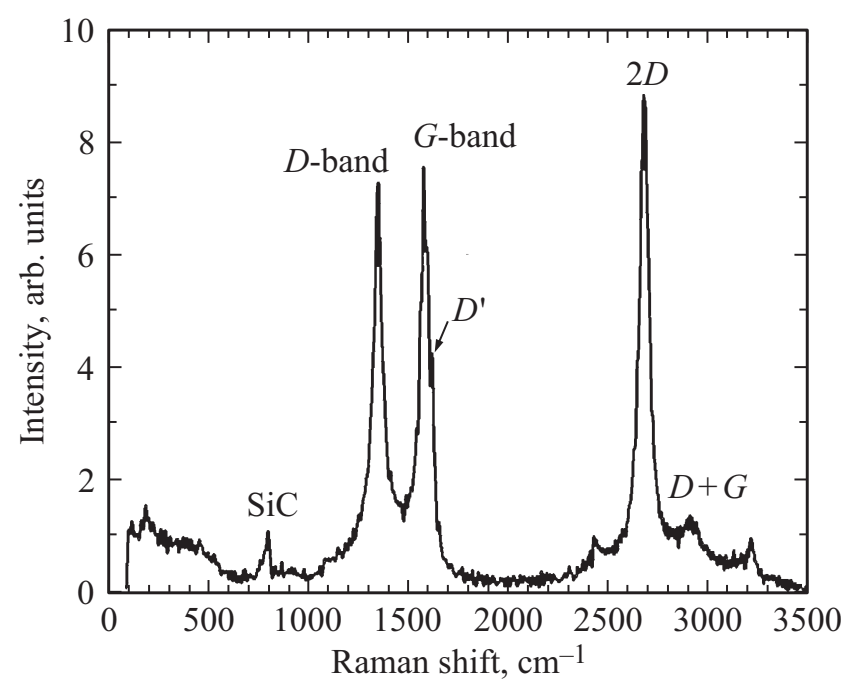

Рис. 6. Рамановский спектр типа III от непрозрачного слоя углерода на $\mathrm{SiC} / \mathrm{Si}$. 


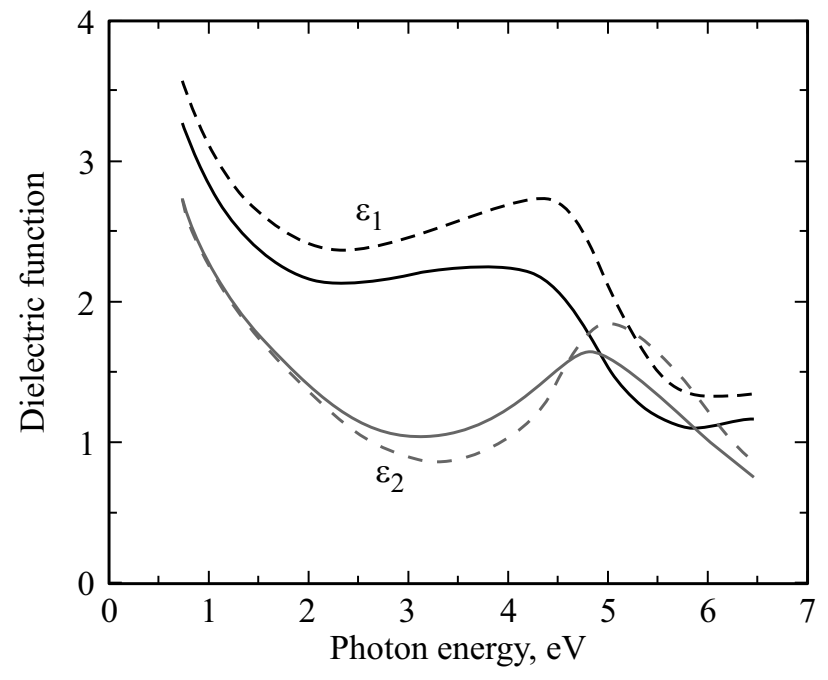

Pис. 7. Зависимость вещественной $\varepsilon_{1}$ и мнимой $\varepsilon_{2}$ частей диэлектрической проницаемости непрозрачного слоя углерода на $\mathrm{SiC} / \mathrm{Si}$ от энергии фотонов. Сплошная линия - измеренная зависимость реального образца, пунктирная - пересчитанная зависимость с учетом шероховатости и переходного слоя.

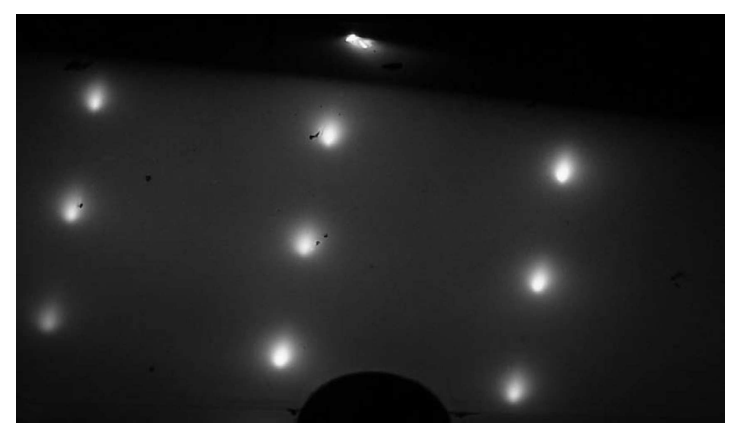

Рис. 8. Электронограмма образца $\mathrm{C} / \mathrm{SiC} / \mathrm{Si}(111) 4^{\circ}$, полученная электронографом ЭМР-100 при энергии электронов $50 \mathrm{keV}$. Поликристаллическая фаза отсутствует.

ческой проницаемости непрозрачной углеродной наноструктуры очень похожа внешне на соответствующие зависимости высокоориентированного пиролитического графита HOPG [16]. Разница между ними заключается в том, что мнимая часть диэлектрической проницаемости $\varepsilon_{2}$ графита HOPG проходит примерно в 6-8 выше, а вещественная часть $\varepsilon_{1}$ примерно в 2-2.5 раза выше. Т. е. оптические свойства выращенных непрозрачных углеродных структур похожи на свойства графита HOPG, но HOPG значительно менее прозрачен.

Исследования упорядоченности углеродных наноструктур дифракцией быстрых электронов на отражение показали, что при малых временах второй стадии конверсии качество кристаллической структуры углеродных слоев близко к эпитаксиальным, но при увеличении времени конверсии качество структур заметно падает вплоть до поликристалла. Наиболее упорядоченными углеродные слои растут на вицинальной поверхности
$\mathrm{Si}(111)$ с $4^{\circ}$ отклонением. Типичная дифрактограмма такого слоя толщиной 50-100 nm при времени конверсии 15-25 min показана на рис. 8. Наихудшая упорядоченность, соответствующая поликристаллу, получается на поверхности (110), что неудивительно, учитывая очень большую шероховатость углеродных структур (рис. $3, d)$. На поверхности (100) вырастают структуры с промежуточным качеством. Эпитаксиальные углеродные структуры удается получить достаточно редко и небольшой толщины $<50 \mathrm{~nm}$. Это также легко объяснить, учитывая, что слой $\mathrm{SiC}$, получаемый на первой стадии конверсии, существенно тоньше и хуже по качеству, чем на $(111)[10,12]$.

Интересно сопоставить свойства углеродных слоев, полученных двухстадийной конверсией из кремния, и слоев, полученных одностадийной конверсией из промышленных подложек $\mathrm{SiC}-4 \mathrm{H}$ и $\mathrm{SiC}-6 \mathrm{H} \mathrm{c}$ помощью реакции (9) при той же температуре $1350^{\circ} \mathrm{C}$. Прежде всего отметим, что разницы между результатами на политипах 4Н и 6Н замечено не было. Углеродные слои получаются примерно такой же толщины, возможно чуть меньше, но гораздо худшего качества. Дифрактограммы полученных слоев соответствуют чисто аморфному материалу. Рамановский спектр образцов также сильно отличается, в частности, на рис. 9 приведен спектр образца, полученного с помощью реакции конверсии (9) из $\mathrm{SiC}-6 \mathrm{H}$ при времени конверсии $25 \mathrm{~min}$ и давлении $p_{\mathrm{CF}_{4}}=60$ Torr. Видно, что углеродный слой является полностью непрозрачным, так как линии $\mathrm{SiC}$ вообще не видны. Линия $G$-band $\left(1590 \mathrm{~cm}^{-1}\right)$ гораздо выше линии $D$-band $\left(1345 \mathrm{~cm}^{-1}\right)$. Линия $2 D\left(2690 \mathrm{~cm}^{-1}\right)$ почти не видна на фоне высокой линии $G^{\prime}\left(2720 \mathrm{~cm}^{-1}\right)$. Также присутствуют дополнительные линии $2470 \mathrm{~cm}^{-1}$ и $3250 \mathrm{~cm}^{-1}$. На наш взгляд, такая принципиальная разница в свойствах углеродных слоев может быть объяснена

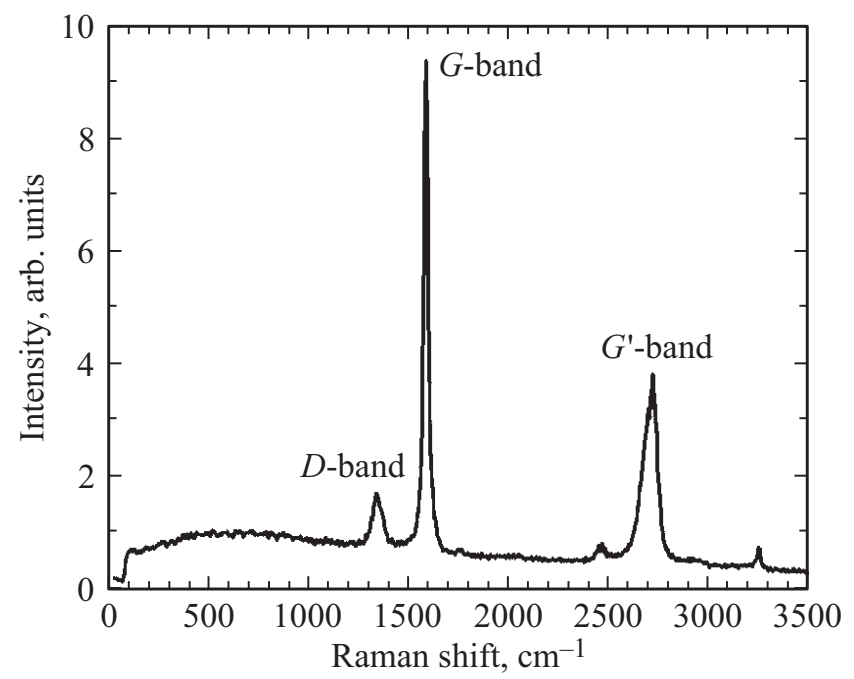

Рис. 9. Рамановский спектр от непрозрачного слоя углерода, полученного в результате реакции (9) на промышленном $\mathrm{SiC}-6 \mathrm{H}$. 
либо разницей между кубическим и гексагональными политипами, либо наличием в $\mathrm{SiC}-3 \mathrm{C}$, полученным на первой стадии конверсии, заметного количества углеродновакансионных структур, состоящих из почти плоского кластера из 4 атомов углерода с длиной связей $1.57 \AA$ и находящейся на расстоянии $2.0 \AA$ от него пустоты диаметром $1.9 \AA$ [14]. Такие образования могут играть важную роль в ориентации углеродных слоев на стадии „схлопывания“.

\section{4. Заключение}

Итак, в настоящей работе предложен новый метод получения ориентированных наноструктурированных слоев углерода на кремнии. Метод заключается в двухстадийном процессе конверсии кремния в углерод через карбид кремния кубического политипа. Конверсия осуществляется только путем согласованных химических реакций замещения. На первой стадии первая половина атомов кремния согласованно замещается на атомы углерода за счет реакции с СО (8), на второй стадии вторая половина атомов кремния согласованно замещается на атомы углерода за счет реакции с $\mathrm{CF}_{4}(9)$. Ориентация слоев углерода осуществляется исходной алмазоподобной кристаллической структурой кремния. Показано, что в зависимости от исходной ориентации подложки, давления газа $\mathrm{CF}_{4}$ и времени второй стадии реакции можно получать различные углеродные структуры, которые по рамановскому спектру условно разделяются на три типа: I (рис. 4), II (рис. 5) и III (рис. 6). Углерод типа I является прозрачным, типа II - полупрозрачным, типа III - непрозрачным, но даже непрозрачный углерод типа III в несколько раз прозрачнее графита HOPG. Выполненные исследования позволяют предположить, что рост углеродных структур из $\mathrm{SiC}-3 \mathrm{C}$ (вторая стадия конверсии) идет по двум конкурирующим механизмам. Первый механизм рост за счет согласованного замещения атомов $\mathrm{Si}$ в $\mathrm{SiC}-3 \mathrm{C}$ на атомы C, как показано на рис. 1. Данный механизм обеспечивает упорядоченный рост плоских углеродных структур, возможно, с преимущественной $s p^{3}$ гибридизацией, поскольку эти структуры весьма прозрачны. Данный механизм имеет место до тех пор, пока не закончится $\mathrm{Si}-3 \mathrm{C}$ в тонкой пленке, полученной на первой стадии конверсии. Весьма вероятно, что углеродно-вакансионные структуры, которые в изобилии имеются в данном $\mathrm{Si}-3 \mathrm{C}$ играют важную роль в упорядочении углеродных структур, получающихся при „схлопывании“ кристаллической решетки $\mathrm{SiC}$ в C (так как в промышленном $\mathrm{SiC}$ этот механизм роста при той же температуре $1350^{\circ}$ отсутствует). Второй механизм роста - классический, атомы $\mathrm{Si}$ за счет упругих напряжений интенсивно поступают на поверхность растущей углеродной структуры, где вступают в реакцию с газом $\mathrm{CF}_{4}$. Такой механизм приводит к шероховатым аморфнополикристаллическим слоям углерода с преимуществен- ной $s p^{2}$ гибридизацией, поскольку данные слои углерода непрозрачные. Тем не менее такие слои все равно в несколько раз более прозрачные, чем графит НOPG. Кроме того, у графита в рамановском спектре линия $D$-band отсутствует, а в данных слоях она достаточно интенсивная. Второй механизм, по-видимому, имеет место всегда, но скорость его сильно зависит от типа проводимости и ориентации поверхности исходного кремния. В тех случаях, когда рост по первому механизму сменяется ростом по второму механизму, можно получить двухслойную углеродную структуру с границей раздела между $s p^{3}$ - и $s p^{2}$-гибридизацией. Возможно, что добавление в $\mathrm{CF}_{4}$ водорода $\mathrm{H}_{2}$, позволит увеличить долю $s p^{3}$-гибридизации, как показано в работе [20].

\section{Список литературы}

[1] W.G. Spitzer, D.A. Kleinman, C.J. Frosch. Phys. Rev. 113, 133 (1959).

[2] J. Graul, E. Wagner. Appl. Phys. Lett. 21, 410 (1972).

[3] В.Г. Дубровский, Г.Э. Цырлин, В.М. Устинов. ФТП 43, 1585 (2009).

[4] J. Li, L. An, C. Lu, J. Liu. Nano Lett. 6, 148 (2006).

[5] M. Kumar, S. Kumar, N. Chauhan, D.S. Kumar, V. Kumar, R. Singh. Semicond. Sci. Tech. 32, 085012 (2017).

[6] M.V. Dorogov, A.N. Priezzheva, S. Vlassov, I. Kink, E. Shulga, L.M. Dorogin, R. Lohmus, M.N. Tyurkov, A.A. Vikarchuk, A.E. Romanov. Appl. Surf. Sci. 246, 423 (2015).

[7] С.К. Гордеев, С.А. Кукушкин, А.В. Осипов, Ю.В. Павлов. ФTT 42, 2245 (2000).

[8] Y. Gogotsi, S. Welz, D.A. Ersoy, M.J. McNallan. Nature 411, 283 (2001)

[9] M.G. Jeong, S.H. Yoon, Y.S. Chun, E.S. Lee, D.-S. Lim. Carbon 79, 19 (2014).

[10] С.А. Кукушкин, А.В. Осипов, Н.А. Феоктистов. ФТТ 56, 1457 (2014).

[11] S.A. Kukushkin, A.V. Osipov. J. Phys. D 50, 464006 (2017).

[12] S.A. Kukushkin, A.V. Osipov. J. Phys. D 47, 313001 (2014).

[13] С.А. Кукушкин, А.В. Осипов. ФТТ 60, 1841 (2018).

[14] S.A. Kukushkin, A.V. Osipov. Physica B 512, 26 (2017).

[15] С.А. Кукушкин, А.В. Осипов. ФТП 47, 1575 (2013).

[16] G.E. Jellison, Jr., J.D. Hunn, Ho Nyung Lee. Phys. Rev. B 76, 085125 (2007).

[17] Detonation Nanodiamonds: Science and Applications / Eds A. Vul', O. Shenderova Pan Stanford Publishing, Singapore (2014).

[18] J.-Ch. Arnault. Nanodiamonds. Advanced Material Analysis, Properties and Applications. Elsevier, Cambridge (2017).

[19] Е.А. Беленков, В.В. Ивановская, А.Л. Ивановский. Наноалмазы и родственные углеродные наноматериалы. УРО РАН Екатеринбург, (2008).

[20] А.Е. Алексенский, М.В. Байдакова, А.Я. Вуль, А.Т. Дидейкин, В.И. Сиклицкий, С.П. Вуль. ФТТ 42, 1531 (2000).

Редактор Ю.Э. Китаев 